\title{
USE OF THE "ACTION INTEGRAL" \\ IN EW STUDIES
}

\author{
by \\ G W Anderson \\ and \\ F W Neilson \\ May 1959
}




\section{DISCLAIMER}

This report was prepared as an account of work sponsored by an agency of the United States Government. Neither the United States Government nor any agency Thereof, nor any of their employees, makes any warranty, express or implied, or assumes any legal liability or responsibility for the accuracy, completeness, or usefulness of any information, apparatus, product, or process disclosed, or represents that its use would not infringe privately owned rights. Reference herein to any specific commercial product, process, or service by trade name, trademark, manufacturer, or otherwise does not necessarily constitute or imply its endorsement, recommendation, or favoring by the United States Government or any agency thereof. The views and opinions of authors expressed herein do not necessarily state or reflect those of the United States Government or any agency thereof. 


\section{DISCLAIMER}

Portions of this document may be illegible in electronic image products. Images are produced from the best available original document. 


\section{Presented at CONFERENCE ON EXPLODING WIRES Boston, Massachusetts. April 1959}

\section{LEGAL NOTICE}

This report was prepared as an account of Government sponsored work. Neither the United States, nor the Commission, nor any person acting on behalf of the Commission:

A. Makes any warranty or representation, expressed or implied, with respect to the accuracy, completeness, or usefulness of the information contained in this report, or that the use of any information, apparatus, method, or process disclosed in this report may not infringe privately owned rights; or

B. Assumes any liabilities with respect to the use of, or for damages resulting from the use of any information, apparatus, method, or process disclosed in this report.

As used in the above, "person acting on behalf of the Commission" includes any employee or contractor of the Commission, or employee of such contractor, to the extent that such employee or contractor of the Commission, or employee of such contractor prepares, disseminates, or provides access to, any information pursuant to his employment or contract with the Commission, or his employment with such contractor.

Printed in USA. Price $\$ 0.50$. Available from the Office of

Technical Services, Department of Commerce, Washington 25, D. C. 
SCR'-94

TID-4500 (14th Edition)

Physics and Mathematics

SANDIA CORPORATION REPRINT

US̈E OH' 'I'HE' "ACTION INTEGRAL" IN EW STUDIES

by

G. W. Anderson

and

F. W. Neilson 


\section{ABSTRACT}

The "action integral" is defined by $I(t)=\int i^{2} d t$, where $i$ is the current in the exploding wire and $t$ is the time. (The name derives from an inexact analogy with classical mechanics: $i: \dot{x}, d q(=i d t): d x$, and $\left.I: \int \dot{x} d x.\right)$. For many purposes, $I$ is a useful supplement to the energy integral, $U=\int i^{2} r d t$, where $r$ is the resistance of the wire. For example, it is expected that at voltage spike time $\mathrm{I}_{\mathrm{S}}=\mathrm{kA}^{2}$ and $\mathrm{U}_{\mathrm{S}}=\mathrm{k}^{\prime} \ell \mathrm{A}$, where $\mathrm{k}$ and $\mathrm{k}^{\prime}$ are constants of the wire material, and $\ell$ and $\mathrm{A}$ are, respectively, the length and cross-sectional area of the wire. The relation for $I_{S}$ was found experimentally to hold within 10 percent over ranges of 2000:1 in A, 400:1 in $\ell$, and 10:1 in current density. In contrast, the $\mathrm{U}_{\mathrm{S}}$ relation failed to hold for changes in $\ell$ and in current density. For many purposes, the nonlinear behavior of $r$ is expressed more conveniently by $r=r(I)$ than by $r=r(U)$, although neither was found adequate over large ranges of average current density. Machine calculations making use of some of these properties have been completed and will be presented. 


\section{USE OF THE "ACTION INTEGRAL" IN EW STUDIES}

The work on exploding wires at Sandia Corporation has been concerned largely with the electrical behavior of the wire up to the time of the voltage spike. We call this linte lle "lime of burst". Up to the time of burst, the explosion process is relatively uncomplicated by gas discharge effects and is controlled mainly by solid and liquid conduction effects. For the study of the wire in this preburst region, we have found that the so-called "action integral" is a convenient variable. The action integral, or simply the "action", is defined by

$$
I(t)=\int i^{2} d t=\int i d q
$$

where $i$ is the current flowing through the wire and $i=d q / d t$. What we call the action here has in the literature had various names, such as "current heat integral" and "thermal inertia". The name "action" used here results from a superficial similarity between the quantity it represents and the action in classical mechanics, where

$$
\text { action } \approx \int \dot{\mathrm{x}} \mathrm{dx}
$$

The energy dissipated in the wire up to time $t$ is given by

$$
U(t)=\int_{0}^{t} i^{2} r d t
$$

where $r$ is the instantaneous resistance of the wire.

For quasi-static constant pressure heating of the wire with no energy losses and no mechanical work,

$$
d U=i^{2} r d t=f(r) d r
$$


which says that the resistance of the wire depends only on the energy input during the heating, melting, and vaporizing processes. The right-hand equality may be solved for $r$ to show that

$$
r=r\left(\int i^{2} d t\right)
$$

that is, the resistance of the wire is an explicit function of the action. The energy or the temperature may similarly be used as a variable but, as will be shown, neither is as convenient as the action for many purposes. Note that the resistance sannot be expressed as an explicit function of timè, unless the clrcull veliaviur is negligibly affected by the presence of the wire.

It is possible to perform the integrations indicated above, using handbook data for the constants. It is assumed that the metal vapor is nonconducting. The resistance therefore increases very rapldly as the wire evajurates and becomca smaller in diameter. Formally, according to this model, $\mathrm{r} \rightarrow\left(\mathrm{I}_{\mathrm{s}}=\mathrm{I}\right)^{-1 / 2}$ as I approaches the limiting value $I_{s}$, corresponding to complete vaporization. If breakdown does not occur, $I=I_{S}$ corresponds to the beginning of the pause.

Figure 1 compares the observed resistance versus action behavior with that predicted from handbook data. The experimental I was about 6 . percent larger than predicted, which is within the combined uncertainties of the comparison. This 6 percent has been normalized out in the figure. The remaining discrepancy is real and is discussed by Tucker.

Under the assumptions stated, both the energy and the action at the time of burst should be easily scaled with the dimensions of the wire. The energy dissipated should be given by $U_{s}=\ell A U_{v}$, where $\ell$ is the length of the wire, $A$ is its croocsectional area, and $U_{v}$ is the energy per unit volume needed to convert the wire material from solid to vapor under the assumed constant pressure conditions. Similarly, for the action, $I_{S}=A^{2} K$, where $K$ is another constant of the wire material. As both Tucker and Cnare have mentioned, the scaling works well for the action and less well for the energy. That is, $I_{s}$ remains within 10 percent of its predicted value for 2000 -fold changes in $A, 400$-fold changes in $\ell$, and 10-fold changes in $\mathrm{J}$, the current density. The scaling has been at least partially verified for several materials, namely copper, nickel, and iron.

The ambient gas and its pressure were also varied and found not to change $I_{s}$. Finally, the scaling was found to hold for two distinctly different input wave forms--the current step used by Tucker and the sine wave used by. Cnare. 


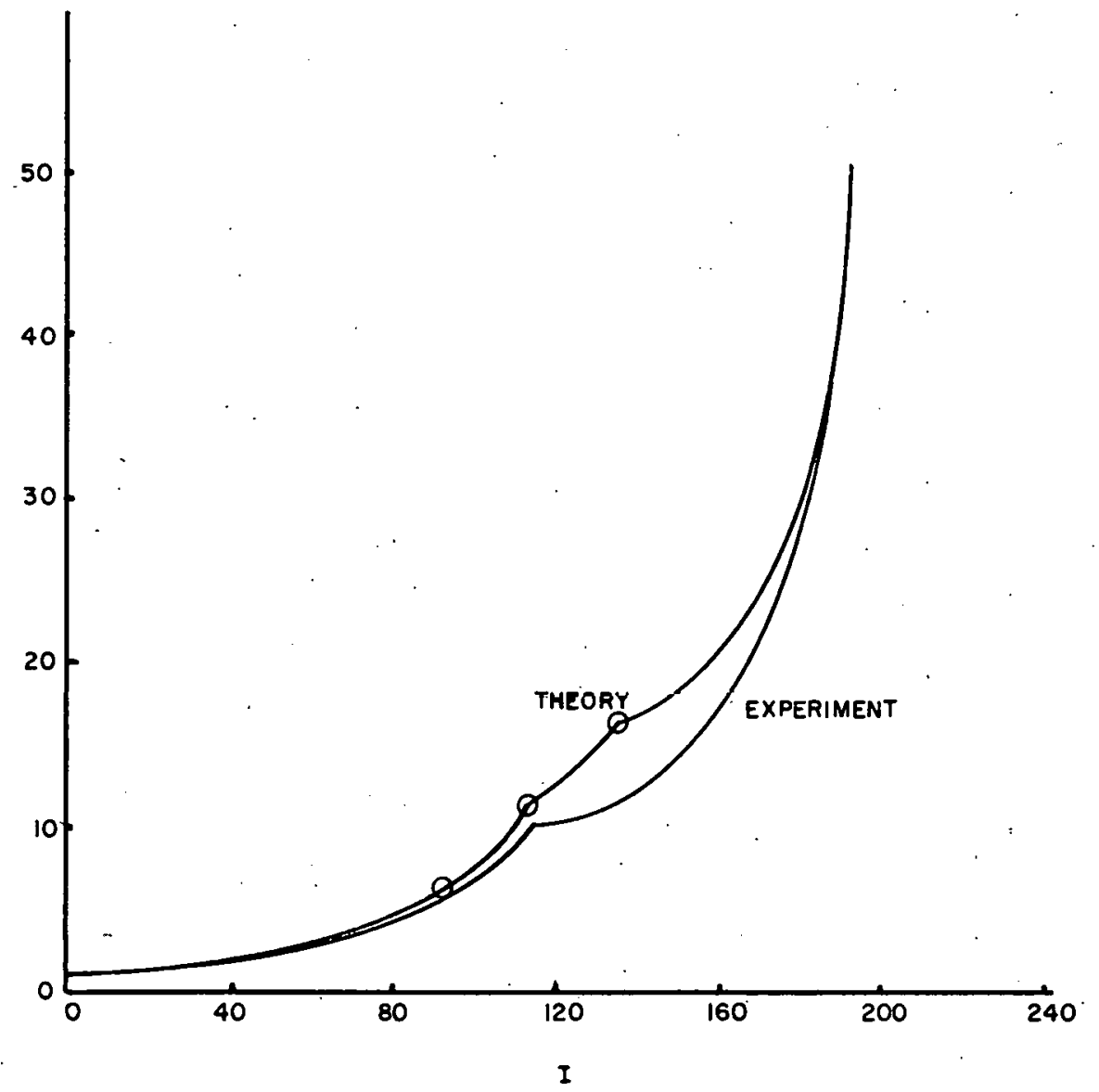

Figure 1. Normalized resistance versus action for silver. Comparison of theory with experiment. Arbitrary scales. 
For the quantity $U_{S}$, it is found necessary to replace the simple scaling law by $U_{\mathrm{S}}=\left(\ell+\dot{\ell}_{\mathrm{o}}\right) \mathrm{AU}_{\mathrm{v}}(\mathrm{J})$. Figures 2 and 3 show the observed behavior of $\mathrm{I}_{\mathrm{s}} / \mathrm{A}^{2}$ and $\mathrm{U}_{\mathrm{S}} / \ell \mathrm{A}$.

The action has been found useful for several purposes. It is more easily measured than the energy since it may be obtained from a measurement of the current only. To measure the energy, it is necessary in most circuits to observe both voltage and current.

For a simple series circuit, which the usual exploding-wire system is, the action is the same for any element in the eircuit. in partliuliat, the cncrgy wastegr in any linear resistance external to the exploding wire is given at time $t$ by $U_{x}(t)$ $=R I(t)$. If the pulse heating of any circuil element external to the exploding wirc is of interest, it may be studied conveniently with the action as the independent variable. The action has proved useful for the prediction of the time of burst because of the constancy of $I_{S}$ over wide rangec of parameter values:

It has been shown that the resistance of the exploding wire may be expressed uniquely and conveniently as a function of the action. This fact has been used in both approximate analytical and machine calculations for the nonlinear circuit problem presented by the LCR exploding-wire circuit. It is also being used in an as yet unfinished machine calculation for the transient field problem; in the interior of the wire.

The problem of analyzing and syulhesizing ourge-cur.rint gencrators for exploding wires is difficult because of the extreme nonlinearity of the wire resistance. The difficulty is threcfold: First, the magnitude of the change in the resistance is large; sometimes a factor of several hundred.. Second, the resistance depends on the energy or the action and not simply on the time or the current. Third, the form of the dependence on the energy or action is fairly complex. The problem, therefore, is of a different order of difficulty from the nonlinear circuit problems which have been successfully handled analytically so far.

The so-called phase plane presentation is helpful for a qualitative picture of the circuit behavior. We have used the current through the circuit, $i$, versus the charge on the capacitor, $q$, as phase plane coordinates. When properly normalized, the $i$ versus $q$ trajectories all lie within a unit circle, the constant energy curves are concentric circles, and the area between the trajectory and the $i=0$ axis is the action. If the resistance is a function of energy or action only, it is constant along concentric circles. A geometric picture of other circuit quantities such as power and voltage may also be constructed. The phase plane technique is a powerful aid in the synthesis of surge-current generators for exploding wires. Figure 4 


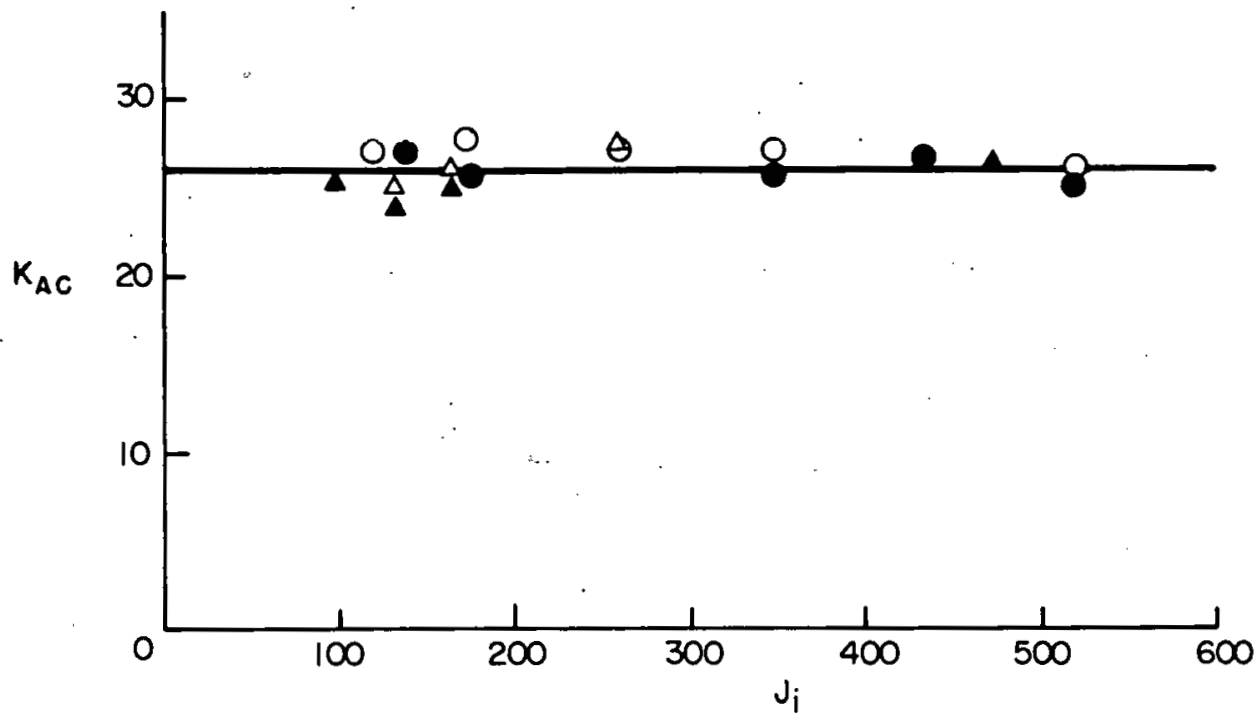

Figure 2. Plot of action to burst $K_{A C}=\int_{0}^{t B} i^{2} d t / A^{2}$ in $10^{-3}$ amp coul $/(\text { cir mil })^{2}$

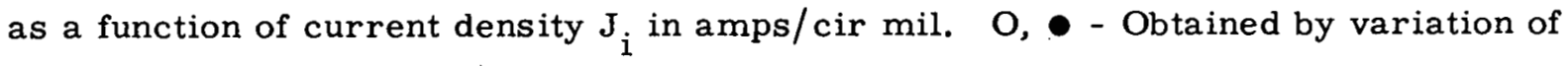
initial cable voltage. $\Delta, \Delta$ - Obtained by variation of initial radius.

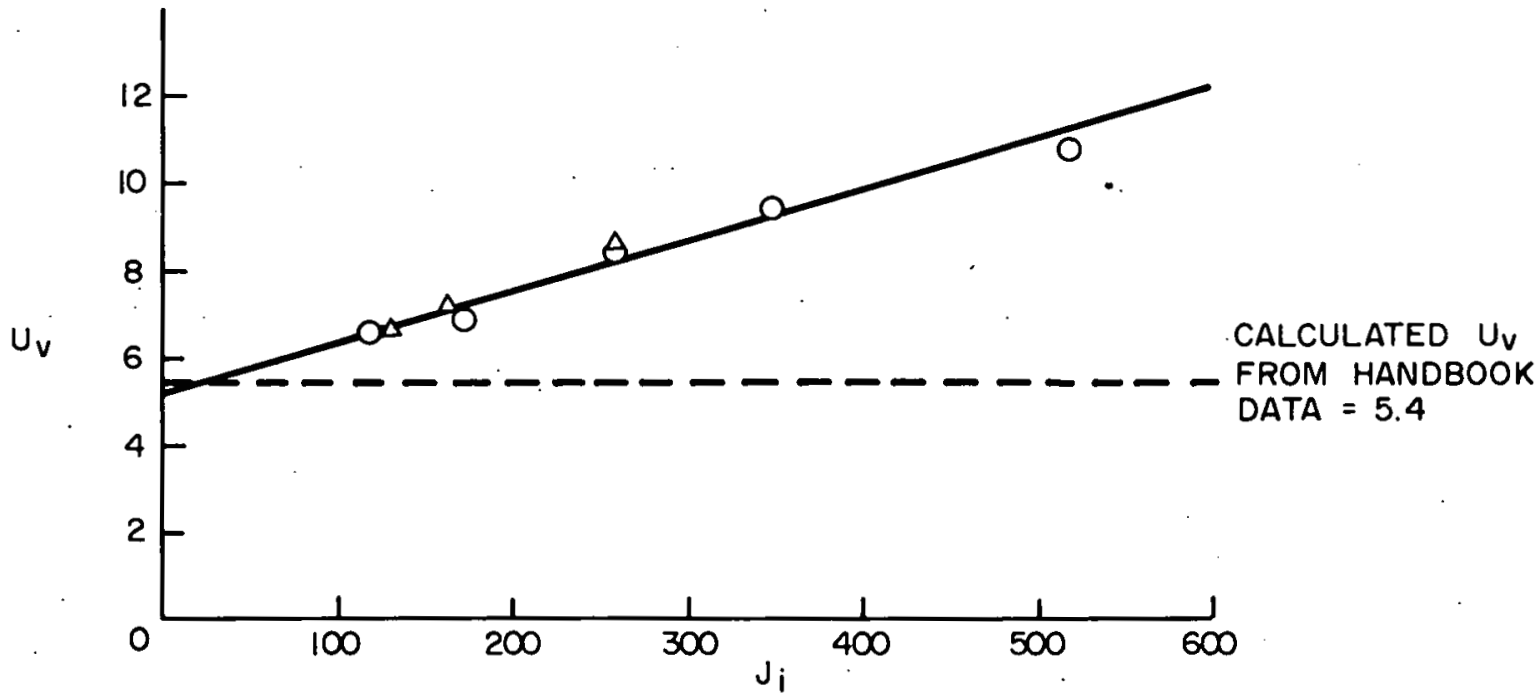

Figure 3. Plot showing the energy to burst dependency on current density in gold. Ordinate is energy per unit volume in $10^{-4}$ joules/cir mil mil. Abscissa is current density in amps/cir mil. O - Obtained by variation of initial cable vóltage. $\Delta$ - Obtained by variation of initial radius. 


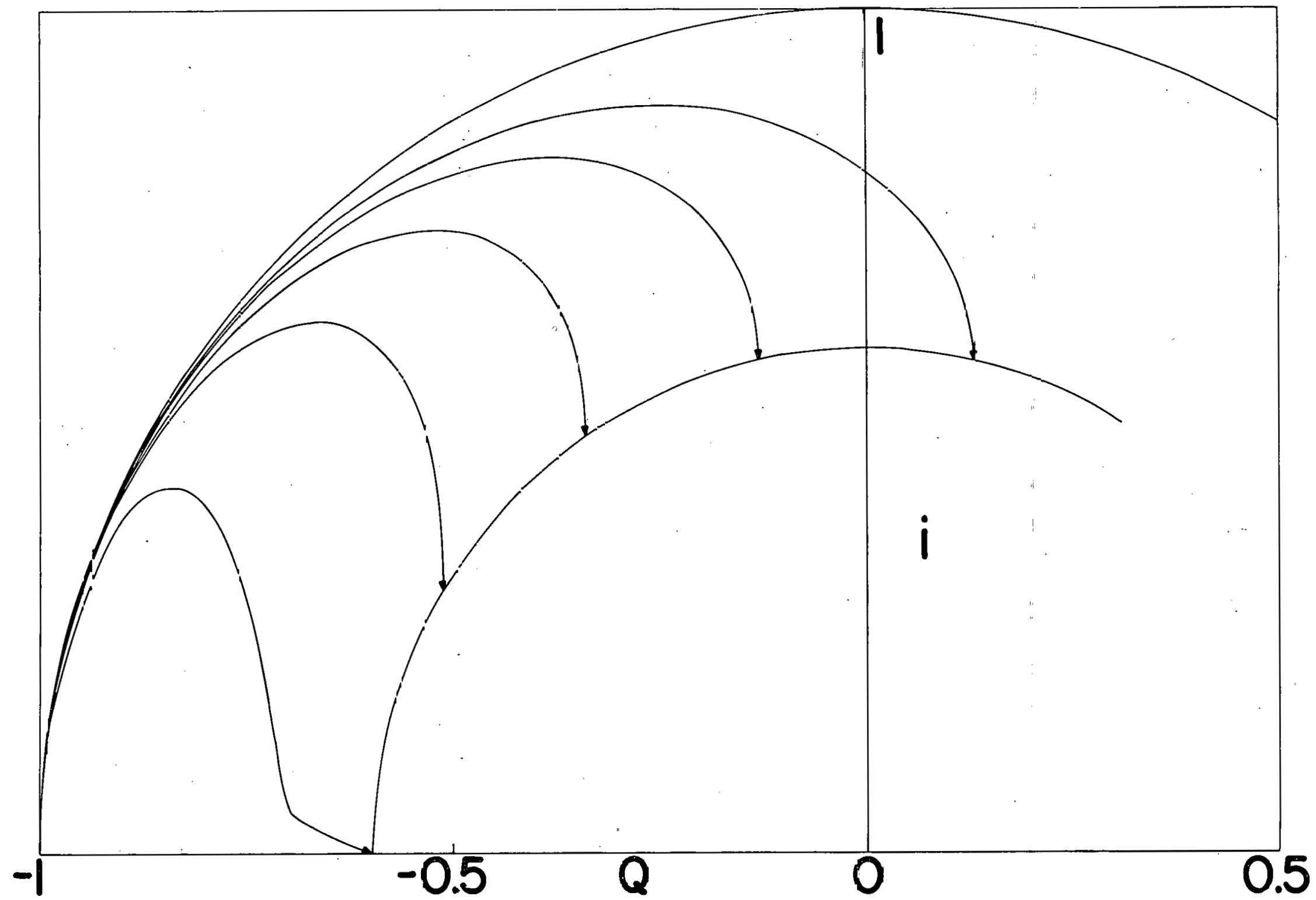

Figure 4. Family of phase plane trajectories for exploding wires. Ordinate normalized current. Abscisse normalized charge left on the capacitor. The family of curves is for wires requiring the same normalized energy to burst but requiring different action to burst. 
shows examples of phase plane trajectories for circuits containing exploding wires.

For a capacitor discharge type of wire-exploding circuit, the governing differential equation is

$$
\left.\begin{array}{rl}
L \cdot d i / d t+(R+r) i+1 / C \int i d t=0 & \\
i=0 \\
\int i d t=-V_{0}
\end{array}\right\} \text { at } t=0
$$

where $r$ is the nonlinear resistance of the exploding wire. As before, $r$ may be written $r=r(I)$ for the preburst region, where the actual $r(I)$ function is like that in Figure 1. This nonlinear ordinary differential equation is easily solved by modern electronic analog computers which have input tables for arbitrary functions. We have used the Sandia REAC analog computer for this study. Each solution required about 15 seconds to run and has a mathematical accuracy of about 1 percent. 